Acta bot. bras. 1(2):171-177 (1988) supl.

\title{
SEMENTES DE CASSIA TORA L.: ESTUDO DA GERMINAÇÃO VISANDO O CONTROLE EM ÁREAS CULTIVADAS
}

\author{
Roberto Andreani Junior (1,2) \\ José Marcos Barbosa (2) \\ Theophilo Salem da Silva (2) \\ Robinson Antônio Pitelli (3) \\ Luiz Mauro Barbosa (2)
}

\begin{abstract}
RESUMO - O trabalho ê um estudo das condiçōes de germinação das sementes de Cassia tora L., planta invasora das culturas em geral e, principalmente, da cultura da soja. Nesta pesquisa, estudouse a quebra da dormência, o efeito da profundidade de semeadura sobre a emergência de plântulas $e$ o potencial de armazenamento, considerando o envelhecimento natural e precoce com o objetivo de um controle mais racional desta espécie. As profundidades de semeadura de $4 \mathrm{a} 6 \mathrm{~cm}$ apresentaram as porcentagens mais altas de emergência das plântulas. A porcentagem de germinação de sementes, logo após a colheita, encontra-se próxima de $42 \%$, decrescendo para $40 \%$, 39\% e 30\%, aproximadamente, nos períodos de armazenamento por 90, 180 e 270 dias, respectivamente, evidenciando uma porcentagem média de germinação próxima de $38 \%$ nos períodos considerados. O processo de escarificação mecânica mostrou-se o mais eficiente para quebra da dormência das sementes.
\end{abstract}

\begin{abstract}
The objective of the present research was to study the germination of Cassia tora L. seeds, which is known to be a weed mainly at soybean plantations and other general crops. This work should verify the effect of planting seeds on different depths on seedling emergence, the potential of seed storage related to natural and accelerated aging and the dormancy breaking process, in order to obtain a more rational control of this species. Seeds which were planted 4 and $6 \mathrm{~cm}$ deep gave best seedling emergence percentagens. After harvest the percentage seed germination of which about $42 \%$, decreased to $40 \%, 39 \%$ and $30 \%$ on storage periods of 90,180 and 270 days respectively, showing an average of $38 \%$ of germination. The best treatment dormancy breaking of there seeds was found to be mechanical scarification.
\end{abstract}

Key-words: Cassia tora L., seeds, germination, weed plant.

\section{Introdução}

O presente estudo das condições de germinação das sementes de Cassia tora é de grande interesse científico e econômico por tratar-se de uma planta invasora bastante agressiva nas lavouras de soja, onde provoca enormes prejuizos, e por apresentar ampla distribuição geográfica nas zonas tropicais e subtropicais.

Lorenzi (1982) destaca a importância de Cassia tora pela sua agressividade na cultura de soja, destacando que uma única planta é capaz de produzir anualmente cerca de 600 sementes, com capacidade de germinação entre 30 a 35\%. Ferreira e Lacca-Buendia (1978) e Aranha et. al. (1972) referem-se a esta espécie comó planta invasora de pastagens e culturas em geral, ocorrendo em quase todas as regiōes do Brasil.

A literatura especializada sobre plantas invasoras, geralmente, apresenta informações insuficientes quanto à biologia e tecnologia das sementes, considerando o seu controle. Dentre os trabalhos sobre fisiologia e tecnologia de sementes, visando o controle de

(1) Bolsista do CNPq.

(2) Instituto de Botânica, Caixa Postal 4005 - Cep: 01051 - Sảo Paulo - SP.

(3) Faculdade de Ciências Agrárias e Veterinárias de Jaboticabal - UNESP. 
plantas invasoras, merecem destaque os seguintes: Cunha e Brandão (1982) destacam a baixa porcentagem de germinação das sementes de plantas invasoras; Toledo e Marcos Filho (1977) correlacionam o longo período de dormência destas sementes com a sua resistência a ambientes desfavoráveis; Lovato e Viggiani (1974) avaliam a influência da profundidade de semeadura na porcentagem de emergência de plântulas e o tempo exigido para germinação das sementes; Machado Neto e Pitelli (1980), ainda referente à profundidade de semeadura, verificam que sementes de amendoim bravo (Euphorbia heterophylla), espécie altamente agressiva, semeadas até $12 \mathrm{~cm}$ de profundidade produzem plântulas normais, apesar de a maioria das plântulas de espécies invasoras emergirem de pequenas profundidades; Condé e Garcia (1985) relacionam o ponto de maturidade das sementes de plantas invasoras com o seu vigor. O presente trabalho apresenta os resultados de estudos sobre a germınaçáo das sementes de Cassia tora e a sua interpretação, ponderando o efeito da profundidade de semeadura na emergência de plântulas, o potencial de armazenamento em função do envelhecimento natural e precoce e a quebra da dormência, visando tornar mais eficiente o seu controle e até mesmo a sua possível erradicação das culturas mais sensíveis a esta espécie.

\section{Material e Métodos}

As sementes de Cassia tora, extraídas manualmente de vagens maduras, foram coIhidas em maio de 1985 numa cultura de soja no município de Jaboticabal, no Estado de São Paulo. Após a secagem ao sol, determinou-se o teor de umidade das sementes.

As sementes foram estocadas num recipiente de plástico fechado, mantidas em câmara seca sem controle de temperatura e retiradas apenas no início de cada experimento.

\section{Ensaio de campo.}

O ensaio para avaliar a emergência de plântulas teve duração de 230 dias e foi realizado em condições de campo na Seção de Sementes e Melhoramento Vegetal do Instituto de Botânica. Para o experimento utilizou-se sacos de polietileno medindo $15 \times 30 X 0,14 \mathrm{~cm}$, contendo como substrato latossolo vermelho-amarelo fase rasa, colocados ao nível do solo.

A semeadura foi realizada com duas sementes por saco plástico, num total de 160 sementes, nas seguintes profundidades: $0,2,4,6$ e $8,0 \mathrm{~cm}$, em quatro repetiçōes, cada uma com quatro sacos plásticos, num total de dezesseis sacos por tratamento. $O$ substrato foi irrigado antes do plantio e, a partir daí, em dias alternados.

\section{Testes de laboratório.}

Os testes de laboratório tiveram a duração de 303 dias, com a avaliação do processo de envelhecimento (natural e precoce) e das técnicas para quebra da dormência das sementes.

a) Envelhecimento natural

Realizado com sementes misturadas com latossolo vermelho-amarelo fase rasa, acondicionadas em recipiente plástico e enterrado no solo do campo experimental. A cada 3 meses, durante 9 meses submeteu-se um lote de sementes aos testes de germinação. 
As sementes foram distribuídas em 7 lotes, os quais foram mantidos por tempos determinados dentro de uma câmara de envelhecimento precoçe sob temperatura constante de $40^{\circ} \mathrm{C}$ e $100 \%$ de umidade relativa, conforme segue: $0,60,120$ e 180 minutos. Em seguida o lote foi retirado da câmara de envelhecimento e transferido para condições de câmara seca por 24 horas, para homogeneização do teor de umidade. Após este período, as sementes foram submetidas aos testes de germinação.

c) Quebra de dormência.

Foram aplicadas as seguintes técnicas:

1. Testemunha - sementes colocadas para germinar sem receber tratamento;

2. ausência de luz - sementes colocadas em caixas plásticas vedadas com papel aluminizado;

3. escarificação mecânica - sementes escarificadas manualmente com auxilio de uma lixadeira elétrica;

4. escarificação química - sementes cobertas com ácido sulfúrico (96\%), dentro de um béquer de $100 \mathrm{ml}$, durante um período de 10 minutos e, a seguir, lavadas em água corrente por 24 horas.

5. baixa temperatura - sementes colocadas em germinador a uma temperatura constante de $5^{\circ} \mathrm{C}$.

O processo de escarificação mecância foi manual, sendo o tegumento da semente levemente perfurado para não injuriar o embrião.

Os testes de germinação em laboratório tiveram a duração de 10 dias, com 4 repetições de 50 sementes.

As sementes foram dispostas sobre papel mata-borrão dentro de caixas plásticas transparentes, medindo $11 \times 11 \times 4 \mathrm{~cm}$, e colocadas num germinador de marca "FANEM" modelo $347 \mathrm{G}$. Durante o processo de germinação, as sementes foram umedecidas quando necessário.

O fotoperiodismo nos germinadores foi de 12 horas de luz e a temperatura mantida constante a $25^{\circ} \mathrm{C}$, exceto o tratamento a baixa temperatura $\left(5^{\circ} \mathrm{C}\right)$.

Para efeito de avaliação, no encerramento de cada teste de germinação, foram feitas as seguintes determinaçōes:

1. Plântula normal: quando apresenta aspecto normal, com raiz primária bem desenvolvida;

2. semente morta: quando comprimida expulsa urn embrião esponjoso e escuro;

3. semente dormente: quando comprimida expulsa um embrião firme e claro;

4. velocidade de germinação das sementes, representa pelo índice de velocidade de germinação (I.V.G.), calculada de acordo com Popinigis (1985);

5. velocidade de emergência de plântulas, representada pelo índice de velocidade de emergência (I.V.E.), calculada de acordo com Popinigis (1985).

$\mathrm{Na}$ análise estatística foram utilizados os testes de Fischer e Tukey, utilizando-se o delineamento em blocos casualizados para o ensaio de campo e inteiramente casualizados para os testes de germinação em laboratório, ambos com quatro repetições de acordo com Gomes (1978). Os valores porcentuais foram transformados em arco seno \%/100 para normalização da distribuição, segundo Snedecor (1966).

\section{Resultados e Discussão}

A Tabela 1 mostra que no armazenamento até 180 dias não houve diferenças significativas nas porcentagens de germinação e nos índices de velocidade de germinação das sementes, indicando que em condições de laboratório a porcentagem de germinação é 
mais ou menos constante, com a média de 38,19\%. Entretanto, no armazenamento por 270 dias verifica-se um decréscimo com diferença significativa na porcentagem de germinação e no índice de velocidade de germinação, evidenciando um sensível declínio no vigor das sementes.

A porcentagem de sementes dormentes no período de armazenamento por 90 dias é inferior as obtidas nos demais tratamentos, embora seja bastante elevada $(30,88 \%)$. A alta porcentagem de dormência de sementes é relatada por Toledo e Marcos Filho (1977) para a maioria das espécies de plantas invasoras, constituindo-se num dos principais fatores para aumentar a capacidade de adaptação destas plantas.

A interpretação destes índices fisiológicas indica que a aplicação de herbicidas poderá ser feita de forma mais racional após a deiscência das vagens, durante um período de 180 dias.

Os valores médios, expressos na Tabela 2, indicam que nas profundidades de 4 e 6 $\mathrm{cm}$ ocorrem as mais altas porcentagens de emergência de plântulas e os maiores índices de velocidade de emergência de plântulas, respectivamente nos períodos por 144 e 115 dias.

TABELA 1. Valores médios e médias do índice de velocidade de germinação (I.V.G.), das porcentagens de sementes dormentes e germinadas obtidos nos períodos de armazenamento pelo método de envelhecimento natural. Valor médio do teor de umidade das sementes obtido após a secagem.

\begin{tabular}{lccc}
\hline & & \multicolumn{2}{c}{$\%$ de sementes } \\
\cline { 3 - 4 } Período de armazenamento (dias) & I.V.G. & $42,41 \mathrm{a}$ & $37,79 \mathrm{ab}$ \\
\cline { 3 - 4 } \multicolumn{1}{c}{} & - & $40,64 \mathrm{a}$ & $30,88 \mathrm{~b}$ \\
90 & $9,05 \mathrm{a}$ & $39,20 \mathrm{a}$ & $49,32 \mathrm{a}$ \\
180 & $8,51 \mathrm{a}$ & 30,54 b & $47,31 \mathrm{a}$ \\
\hline 270 & 5,37 b & 38,19 & 41,82 \\
\% média & 7,64 & - & - \\
Teor de umidade (\%) & 10,70 & $10,10^{* *}$ & $10,17^{* *}$ \\
Teste F & $10,15^{* *}$ & 8,68 & 12,65 \\
Coeficiente de variação (\%) & 16,88 & 6,87 & 10,97 \\
Diferença mínima significativa & 2,49 & & dormentes \\
\hline
\end{tabular}

Obs:- Os valores seguidos pela mesma letra e na mesma coluna não diferem entre si significativamente ao nivel de $5 \%$ de probabilidade, pelo teste Tukey.

Para efeito de análise estatística, os dados em porcentagem foram transformados em arco seno $\sqrt{\% / 100 .}$

Teste $\mathrm{F}=$ Teste estatístico de Fischer.

** $=$ Significativo a nivel de $1 \%$ de probabilidade.

A Tabela 2 mostra também que as semeaduras na superfície do solo e a $2 \mathrm{~cm}$ de profundidade apresentam as menores porcentagens de emergência de plântulas e que 0 valor encontrado na superfície do solo difere estatisticamente dos valores obtidos nas profundidades de 4 e $6 \mathrm{~cm}$. Portanto, verifica-se uma tendência de aumento na porcentagem de emergência de plântulas e nò índice de velocidade de emergência de plântulas à medida que se aumenta a profundidade de semeadura até $6 \mathrm{~cm}$, embora os valores não sejam estatísticamente diferentes. 
TABELA 2. Valores médios da porcentagem e da velocidade de emergência de plântulas, em diferentes profundidades se semeadura, em condiçōes de campo. Período demandado para a emergência das plântulas, nas respectivas profundidades, em condiçōes de campo (período máximo de observação: 230 dias).

\begin{tabular}{cccc}
\hline $\begin{array}{l}\text { Profundidade de } \\
\text { semeadura }(\mathrm{cm})\end{array}$ & $\begin{array}{c}\text { Emergência das } \\
\text { plântulas (\%) }\end{array}$ & $\begin{array}{c}\text { Período demandado para } \\
\text { emergéncia das plântulas } \\
\text { (dias) }\end{array}$ & I.V.E. \\
\hline 0 & $15,53 \mathrm{~b}$ & 16 & 0,0870 a \\
2 & $29,10 \mathrm{ab}$ & 86 & 0,1113 a \\
4 & $35,31 \mathrm{a}$ & 144 & 0,1858 a \\
6 & $37,14 \mathrm{a}$ & 115 & 0,1959 a \\
8 & 31,55 ab & 230 & 0,1265 a \\
\hline Teste F Blocos & $5,52^{*}$ & & 1,94 n.s. \\
Teste F Tratamentos & $4,80^{*}$ & & 0,59 n.s. \\
Coeficiente de variação (\%) & 26,22 & & 87,54 \\
Diferença mínima significativa & 17,57 & & - \\
\hline
\end{tabular}

Obs:- Os valores seguidos pela mesma letra e na mesma coluna não diferem entre si, significativamente ao nivel de $5 \%$ de probabilidade, pelo teste Tukey.

Para efeito de análise estatística, os dados em porcentagem foram transformados em arco seno $\sqrt{\% / 100}$.

Teste $\mathrm{F}=$ Teste estatistico de Fischer.

• = Significativo a nivel de $5 \%$ de probabilidade.

n.s. = não significativo a nivel de $5 \%$ de probabilidade.

Resultados semelhantes foram encontrados por Machado Neto e Pitelli (1980) com sementes de Euphorbia heterophylla (amendoim-bravo) que apresentam baixa porcentagem de emergência de plântulas nas proximidades da superfície do solo. As baixas porcentagens de emergência de plântulas obtidas nas proximidades da superfície do solo podem ser atribuídas à deficiência hídrica, ocasionada pela rápida drenagem da água e pela sua evaporação mais intensa nesse local.

Os valores paramétricos da Tabela 3 mostram que na escarificação mecânica ocorre o maior indice de velocidade de germinação e baixa porcentagem de sementes dormentes num período mais curto, se comparados aos exigidos pelos demais tratamentos. Assim, pode-se admitir que, por ocasião do preparo do solo, para a instalação das culturas de interesse econômico, qualquer processo de escarificação das sementes resultará num aumento significativo na porcentagem de germinação. Por outro lado, verifica-se que a porcentagem de sementes dormentes é alta a baixas temperaturas, podendo-se admitir que as sementes de Cassia tora permanecem viáveis por longo período no solo das regiões mais frias.

Os dados expostos na Tabela 4 evidenciam que as porcentagens de sementes germinadas, dormentes e mortas não apresentam diferenças estatísticas entre os tratamentos efetuados (60, 120 e 180 minutos). Observa-se também que os valores de porcentagens de sementes germinadas e de sementes dormentes são próximos nos referidos períodos de envelhecimento. Estes valores, aliados aos obtidos com o método do envelhecimento natural (tabela 1), evidenciam o grande potencial de armazenamento das sementes de Cassia tora, que é mantido sem perdas significativas na qualidade fisiológica das sementes por 180 dias, permitindo a sobrevivência das sementes no solo por longo período, mesmo em condições bastante adversas. 
TABELA 3. Valores médios do índice de velocidade de germinação (I.V.G.) e porcentagens de sementes germinadas, dormentes e mortas obtidas nos processos de quebra de dormência. Periodo demandado para o início e final do experimento.

\begin{tabular}{|c|c|c|c|c|c|c|}
\hline \multirow{3}{*}{$\begin{array}{l}\text { Tratamentos } \\
\text { Testemunha }\end{array}$} & \multirow{2}{*}{ I.V.G. } & \multicolumn{3}{|c|}{$\%$ de sementes } & \multirow{2}{*}{\multicolumn{2}{|c|}{$\underset{1^{\mathrm{a}}}{\text { contagens (dias) }}$ Final }} \\
\hline & & germinadas & dormentes & mortas & & \\
\hline & $5,59 \quad b$ & $42,41 a b$. & $39,79 \quad b$ & 21,39 b & 3 & 9 \\
\hline Ausência de luz & $4,19 \quad b$ & 34,75 b & 38,64 bc & 32,23 a & 3 & 9 \\
\hline Escarificação mecânica & $15,09 \mathrm{a}$ & 55,51 a & $22,67 \quad d$ & $24,26 a b$ & 1 & 8 \\
\hline Escarificação química & 19,27 a & $45,69 a b$ & 27,17 bcd & $25,66 a b$ & 1 & 7 \\
\hline Baixa temperatura & $0,17 \quad b$ & $12,86 \quad c$ & 75,41 a & $4,91 \quad c$ & 13 & 22 \\
\hline Teste F & $13,99^{* * *}$ & $21,71^{* *}$ & $39,64^{* *}$ & $22,62^{* *}$ & & \\
\hline Coeficiente de variação (\%) & 45,25 & 17,91 & 16,16 & 19,75 & & \\
\hline $\begin{array}{l}\text { Diferença mínima } \\
\text { significativa }\end{array}$ & 8,68 & 14,83 & 14,25 & 9,20 & & \\
\hline
\end{tabular}

Obs:- Os valores seguidos pela mesma letra e na mesma coluna não diferem entre si significativamente a nivel de $5 \%$ de probabilidade, pelo teste Tuckey.

Para efeito de análise estatística, os dados em porcentagem foram transformados em arco seno $\sqrt{\% / 100}$.

Teste $\mathrm{F}=$ teste estatístico de Fischer.

*" = significativo a nível de $1 \%$ de probabilidade.

TABELA 4. Valores médios das porcentagens de sementes germinadas, dormentes e mortas obtidos no teste de envélhecimento precoce por períodos pré-determinados.

\begin{tabular}{cccc}
\hline \multirow{2}{*}{$\begin{array}{l}\text { Tratamentos } \\
\text { (tempo em minutos) }\end{array}$} & \multicolumn{3}{c}{ \% de sementes } \\
\cline { 2 - 4 } & germinadas & domentes & mortas \\
\hline 0 & 42,41 a & 39,79 b & 21,39 a \\
60 & 35,61 b & 47,87 a & 18,93 a \\
120 & 37,16 ab & 43,55 a & 23,42 a \\
180 & 38,41 ab & 45,57 a & 18,85 a \\
\hline Teste F & $4,69^{*}$ & $4,90^{*}$ & 1,58 n.s. \\
Coeficiente de variação (\%) & 6,70 & 7,00 & 16,83 \\
Diferença mínima significativa & 5,57 & 6,42 & - \\
\hline
\end{tabular}

Obs:- Os valores seguidos pela letra e na mesma coluna não diferem entre si significativamente ao nível de $5 \%$ de probabilidade pelo teste Tuckey.

Para efeito de análise estatística, os dados em porcentagem foram transformados em arco seno $\sqrt{\% / 100 .}$

Teste $\mathrm{F}=$ Teste estatístico de Fischer.

* = significativo a nivel de $5 \%$ de probabilidade.

n.s. = não significativo a nível de $5 \%$ de probabilidade. 


\section{Conclusões}

a) processo de escarificação mecânica é o de maior eficiência na quebra de dormência das sementes de Cassia tora.

b) As profundidades de semeadura de 4 e $6 \mathrm{~cm}$ resultam em maiores porcentagens de germinação de sementes de Cassia tora.

c) A capacidade de germinação das sementes de Cassia tora diminui lentamente até 180 dias cie armazenamento após a deiscência dos frutos.

d) Com 270 dias de armazenamento, a capacidade de germinação das sementes decresce sensivelmente, apresentando uma porcentagem de $30,54 \%$.

e) Pode-se seguramente admitir que o controle desta espécie poderá ser realizado com maior eficiência se as técnicas aplicadas no preparo do solo e o emprego de herbicidas observarem criteriosamente as porcentagens de emergência de plântulas, os índices de velocidade de emergência de plântulas para as diferentes profundidades e, ainda, se as técnicas de escarificação das sementes forem mais adequadas.

\section{Referências Bibliográficas}

ARANHA, C., BACCHI, O. \& LEITĀO FILHO, H. de F. 1972. Plantas invasoras de culturas. Mucitec: Ministério da Agricultura, São Paulo.

CONDÉ, A.R.C. \& GARCIA, J. 1985. Efeito da época de colheita sobre o potencial de armazenamento das sementes do capim-braquiária em condiçōes ambiantais. Revta bras. Sem. 7: 85-99.

CUNHA, L.H.S. \& BRANDĀO, M. 1982. Frutos, sementes e plântulas das principais plantas daninhas no Estado de Minas Gerais. Infme.agrop. 8: 11-17.

FERREIRA, M.B. \& LACA-BUENDIA, J.P.C. 1978. Espécies consideradas daninhas em áreas cultivadas no Estado de Minas Gerais. Planta dan. 1: 16-26.

GOMES, F.P. 1978. Curso de estatística experimental. Piracicaba, $8^{\circ}$ ed. ESALQ/USP.

LORENZI, H. 1982. Plantas daninhas do Brasil. Edição do autor, Nova Odessa, SP.

LOVATO, A. \& VIGGIANI, P., 1974. Laboratory germination and field emergence of some weed species. Revta agron. 8: 108-112.

MACHADO NETO, J.A. \& PITELLI, R.A., 1980. Efeito da profundidade de semeadura na emergência de Euphorbia heterophylla L. In: Anais do Congresso Brasileiro de Herbicidas e Ervas Daninhas 13은 Ilhéus/Itabuna, BA. Mimeografado, 15 p.

POPINIGIS, F. 1985. Fisiologia da Semente. Ministério da Agricultura, Agiplan, Brasília.

SNEDECOR, G.W. 1966. Métodos estatisticos aplicados a la investigacion agrícola e biológica. Compania Editorial Continental S.A., México.

TOLEDO, F.F. \& MARCOS FILHO, J. 1977. Manual de sementes: tecnologia da produção. Ed. Ceres, São Paulo. 